\title{
Health-related quality of life of partners of adults with haemophilia
}

Sylvia von Mackensen, Karin Lindvall, Sölve Elmståhl, Erik Berntorp

Assessment of health-related quality of life (HRQoL) in haemophilia is important in order to provide information for clinical decision-making and to verify the impact of haemophilia on patients and their partners. A crosssectional single-centre study was performed to assess the health-related quality of life (HRQoL) and burden of the disease on partners of adult patients with haemophilia.

Self-reported outcomes were completed by partners and patients (SF-36, VAS of Interference); partners also completed the Caregivers' Burden Scale.

A total of 108 of 150 eligible partners of adults with haemophilia (72\%) participated. Mean age for partners was 44.7 years (range 20-79) and for patients 47.1 years (range 20-81). The majority of couples were married (65.7\%). Couples reported being together a mean of 19.8 years and had, on average, 1.7 children. Partners of haemophilia patients across all severities reported lower HRQoL in the 'emotional role' domain of SF-36 $(\mathrm{P}=<0.041)$, with highest impairments observed among partners of moderately affected patients. Partners reported significantly less interference with daily life compared to patients $(P<0.001)$. In general, partners reported low burden of haemophilia in the Caregivers' Burden Scale; 'emotional involvement' was the greatest burden in the mild and moderate group; while in the severe group 'general strain' was the greatest burden. Partners of severe haemophilia patients on prophylaxis reported, in general, good HRQoL and low burden of the disease. Partners of moderate patients reported decreased HRQoLandhigherburden. Ourfindingsmaybeofimportance for the care of the ageing person with haemophilia (PWH).

Keywords: partner, haemophilia, caregivers' burden, health-related quality of life, disease impact

Haemophilia is an $\mathrm{x}$-linked recessive bleeding disorder affecting males. According to the residual plasma coagulation factor activity, i.e Factor (F)VIII (haemophilia A) or FIX (haemophilia B) it is possible to distinguish different types of severity: 'severe' with the respective factor activity below $0.01 \mathrm{IU} / \mathrm{ml}(<1 \%)$, 'moderate' with

Sylvia von Mackensen, Institute of Medical Psychology, University Medical Centre Hamburg-Eppendorf, Hamburg, Germany. Email:

s.mackensen@uke.uni-hamburg.de

Karin Lindvall, Lund University, Malmö Centre for Thrombosis and Haemostasis, Malmö, Sweden

Sölve Elmståhl,, Department of Health Sciences, Division of Geriatric Medicine, Lund University, Sweden

Erik Berntorp, Lund University, Malmö Centre for Thrombosis and Haemostasis, Malmö, Sweden

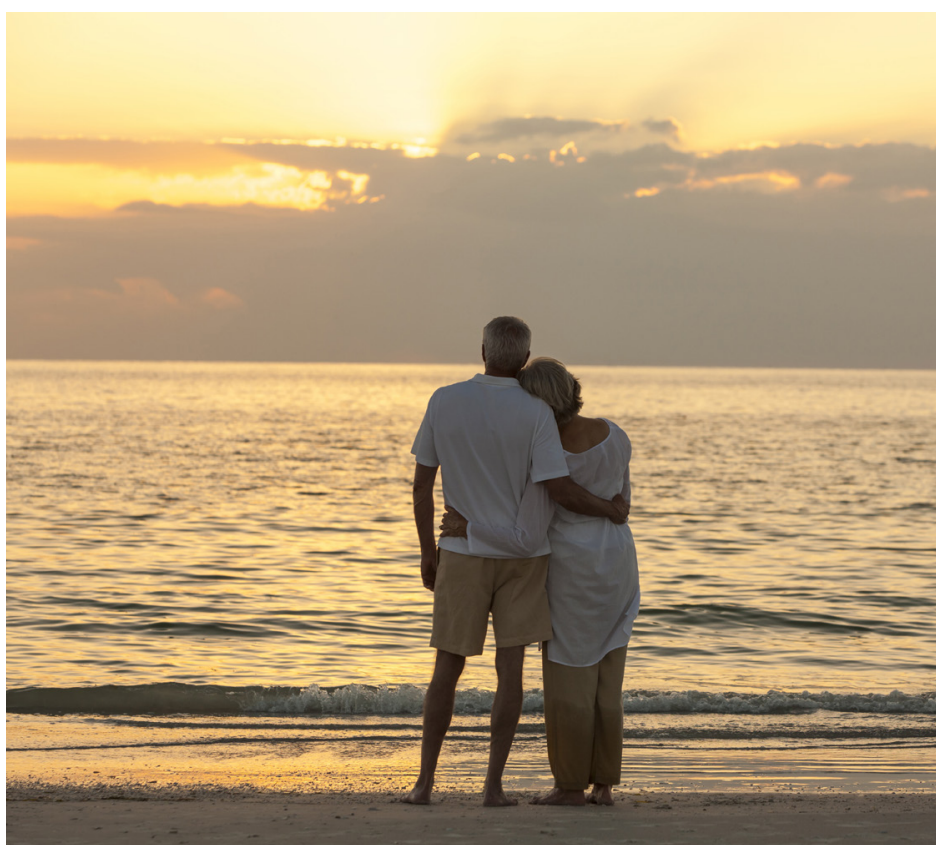

a factor activity between 0.01 and $0.05 \mathrm{IU} / \mathrm{ml}(1-5 \%)$ and 'mild' with a factor activity between 0.05 and 0.40 $\mathrm{IU} / \mathrm{ml}(5-40 \%)$ [1]. Typical symptoms of haemophilia patients are recurrent and spontaneous bleeds in joints and muscles, which can lead to arthropathy or disability [2]. Patients are treated intravenously with FVIII or FIX replacement therapy when bleeding occurs (on-demand) or regularly 1-3 times a week and continuously in order to prevent bleeds (prophylaxis) [3]. Recent studies have clearly shown the advantages of prophylactic treatment [4-6] for haemophilia. Initially, patients were of advanced age at the onset of prophylaxis, most had a severe form of the disease and had already developed haemophilia arthropathy [7]. A number of these have undergone orthopaedic interventions such us ankle arthrodesis or total hip/knee replacement. Start of prophylaxis at younger ages has resulted in better joints and radiological joint scores. In these patients, an improvement in their healthrelated quality of life (HRQOL) could be demonstrated [8].

The assessment of HRQoL in families with haemophilia is important both to provide information for clinical decision-making [4] and to verify the impact of haemophilia on patients as well as on their partners. Advances in haemophilia care and prophylactic treatment throughout life have improved HRQoL for patients. Older people with haemophilia have different needs compared to the younger population. In countries with a long 


\begin{tabular}{|c|c|c|c|c|}
\hline $\begin{array}{l}\text { Total numbers of } \\
\text { patients in registry }\end{array}$ & $\begin{array}{l}\text { Severe haemophilia } \\
\qquad(n=92)\end{array}$ & $\begin{array}{l}\text { Moderate haemophilia } \\
\qquad(n=37)\end{array}$ & $\begin{array}{l}\text { Mild haemophilia } \\
\qquad(n=114)\end{array}$ & $\begin{array}{l}\text { Total } \\
(n=243)\end{array}$ \\
\hline Non-eligible patients & 41 & 9 & 43 & 93 \\
\hline Single & 26 & 4 & 23 & 53 \\
\hline Living with parents & 9 & 1 & 3 & 13 \\
\hline Died during enrollment period & 1 & 2 & 4 & 7 \\
\hline Belonging to another centre & 1 & 2 & 12 & 15 \\
\hline Emigrated & 0 & 0 & 1 & 1 \\
\hline Liver transplantation & 1 & 0 & 0 & 1 \\
\hline Dementia & 1 & 0 & 0 & 1 \\
\hline Language problems & 2 & 0 & 0 & 2 \\
\hline Eligible couples & 51 & 28 & 71 & 150 \\
\hline Did not want to Participate & 4 & 4 & 13 & 21 \\
\hline Did not respond & 0 & 3 & 18 & 21 \\
\hline Included couples (\% of eligible) & $47(92 \%)$ & $21(75 \%)$ & $40(56 \%)$ & $108(72 \%)$ \\
\hline
\end{tabular}

tradition of prophylaxis, patients with haemophilia have achieved almost the same life expectancy as the general population [9] and face the same problems related to co-morbidities and cognitive impairments as the general population [10-12]. These co-morbidities may influence their HRQoL [13] and are likely to exert a further impact on the burden of partners of haemophilia patients in terms of financial, physical and psychological considerations. The occurrence of HIV infection and its challenging treatment (especially before the introduction of HAART) might have a direct psychological or emotional impact on partners of haemophilia patients. The requirements for help and support for the partner of a person with haemophilia will change over time, as the chronically ill patient's needs increase.

Therefore, the challenges for the haemophilia comprehensive care team will be to meet new needs and demands - not only from patients - but also from their families. There is a lack of information regarding both the degree to which the lives of partners of adult patients are influenced by the chronic disease and how the HRQoL of adult haemophilia patients affects the HRQoL of their partners.

The primary objective of this study was to investigate HRQoL and the burden on partners of adult patients with haemophilia in order to achieve a better understanding of the needs of and the demands facing partners of adults with haemophilia. Based on the results of the study we want to develop strategies to meet the demands that partners of haemophilia patients have towards a haemophilia comprehensive care team.

\section{Materials and methods}

A cross-sectional single-centre study was performed at the Haemophilia Treatment Centre (HTC) in Malmö, Sweden to assess the burden of the disease on partners of patients with haemophilia. The study was approved by the Regional Ethical Review Board in Lund, Sweden. Informed consent was obtained prior to study entry from both partners and patients.

\section{Study population}

Two hundred and forty-three adult patients with severe, moderate or mild haemophilia A or B were identified from the Malmö University Hospital (UMAS) Haemophilia Database, a centre-based registry for patients with congenital bleeding disorders [14]. Inclusion criteria were patients aged $>18$ years and having a partner, i.e. married, cohabitating or living apart.

Potential participants were notified about the study by a letter from the HTC. For those who did not respond the first time, a maximum of two reminders were sent. Patients were asked if they had a partner, and if they and their partners would like to participate in the study. There were no additional criteria for participation by a partner. If the couple agreed to participate, a home visit was made at which time the patient and his partner independently completed self-reported instruments including the SF-36 and VAS interference with daily life. In addition, partners completed the Caregivers' Burden Scale. Information about the clinical status of haemophilia patients (including the orthopaedic status) was extracted from the UMAS Haemophilia Database. The enrolment period was from August 2010 to June 2012.

\section{Instruments used}

- SF-36 (Short Form Health Survey) is a generic HRQoL questionnaire for adults, consisting of 36 items pertaining to eight dimensions ('physical functioning', 'role physical functioning', 'bodily pain', 'general health', 'vitality', 'social functioning', 'role emotional functioning' and 'mental health'). Scores range from 0 (worst quality of life) to 100 (best quality of life) [15]. Summary scores for a physical component score (PCS) and a mental component score (MCS) can be derived [15]. Age- and gender-specific norms for the general Swedish population are available for this instrument [16].

- Visual Analogue Scale (VAS) is often used for measuring pain but has also been incorporated into HRQoL instruments [17]. In this study 0 was considered as no 
Table 2: Clinical characteristics of study population

\begin{tabular}{|c|c|c|c|c|c|}
\hline Clinical data & $\begin{array}{l}\text { Severe haemophilia } \\
(n=47) \\
N(\%)\end{array}$ & $\begin{array}{l}\text { Moderate haemophilia } \\
\qquad(\mathrm{n}=21) \\
\mathrm{N}(\%)\end{array}$ & $\begin{array}{l}\text { Mild haemophilia } \\
\qquad \begin{array}{c}(\mathrm{n}=40) \\
\mathrm{N}(\%)\end{array}\end{array}$ & $\begin{array}{c}\text { Total population } \\
(n=108) \\
N(\%)\end{array}$ & $P$ value \\
\hline \multicolumn{6}{|l|}{ Type of haemophilia } \\
\hline - $A$ & $37(78.7)$ & $15(71.4)$ & $29(72.5)$ & $81(75)$ & n.s \\
\hline$\therefore B$ & $10(21.3)$ & $6(28.6)$ & $11(27.5)$ & $27(25)$ & \\
\hline \multicolumn{6}{|l|}{ Treatment } \\
\hline - Prophylaxis & $45(95.7)$ & $6(28.6)$ & $1(2.5)$ & $52(48.1)$ & $<0.0001$ \\
\hline - On-demand & $0(0)$ & $15(71.4)$ & $39(97.5)$ & $54(50.0)$ & \\
\hline - ITI & $2(4.3)$ & $0(0)$ & $0(0)$ & $2(1.9)$ & \\
\hline \multicolumn{6}{|l|}{ Inhibitor } \\
\hline - current & $2(4.3)$ & $0(0)$ & $0(0)$ & $2(1.9)$ & n.s \\
\hline - no & $39(83)$ & $21(100)$ & $39(97.5)$ & 99 (91.7) & \\
\hline - previous & $6(12.8)$ & $0(0)$ & $1(2.5)$ & $7(6.5)$ & \\
\hline HCV RNA positive & $13(27.7)$ & $7(33)$ & $9(22.5)$ & 29 (26.9) & n.s \\
\hline HIV positive & $5(10.6)$ & $2(9.5)$ & $0(0)$ & $7(6.5)$ & n.s \\
\hline & $\mathrm{M} \pm \mathrm{SD}$ (range) & $M \pm S D$ (range) & $\mathrm{M} \pm \mathrm{SD}$ (range) & $\mathrm{M} \pm \mathrm{SD}$ (range) & \\
\hline HJHS joint score & $\begin{array}{c}19.3 \pm 17.6 \\
(0-57)\end{array}$ & $\begin{array}{c}11.2 \pm 12.8 \\
(0-43)\end{array}$ & $\begin{array}{c}4.3 \pm 5.6 \\
(0-25)\end{array}$ & $\begin{array}{c}12.4 \pm 15.0 \\
(0-57)\end{array}$ & $<0.0001$ \\
\hline HJHS global gait score & $0.7 \pm 1.1$ & $0.3 \pm 0.5$ & $0.03 \pm 0.8$ & $0.4 \pm 0.8$ & $<0.002$ \\
\hline & $\begin{array}{c}(0-4) \\
\text { Median (range) }\end{array}$ & $\begin{array}{c}(0-1) \\
\text { Median (range) }\end{array}$ & $\begin{array}{c}(0-1) \\
\text { Median (range) }\end{array}$ & $\begin{array}{c}(0-4) \\
\text { Median (range) }\end{array}$ & \\
\hline Age (years) at start of & 5.2 & 27.6 & $49.7^{*}$ & 6.38 & n.s. \\
\hline prophylaxis (n=52) & $(0.8-52.2)$ & $(0.9-59.8)$ & (49.7) & $(0.8-59.8)$ & \\
\hline
\end{tabular}

P-values $<0.05$ were considered statistically significant, n.s. = not significant. * only 1 mild haemophilia patient was on prophylaxis

interference with daily life by haemophilia (physically and mentally) and 100 as highest interference with daily life by haemophilia.

- Caregivers' Burden Scale is a 22-item scale that assesses subjectively experienced burden by a caregiver to a chronically disabled person. The instrument contains questions concerning the following domains ('general strain', 'isolation', 'disappointment', 'emotional involvement' and 'environmental aspects'). The caregiver is asked to choose one of four options (not at all, seldom, sometimes and often) scored 1 to 4 for each question. A mean score of 1 to 1.99 implies low burden, 2 to 2.99 implies medium burden and 3 to 4 implies high burden [18].

- Haemophilia Joint Health Score (HJHS) version 2.0 [19]. The HJHS version 2.0 assesses eight items (swelling, duration of swelling, muscle atrophy, crepitus on motion, flexion loss, extension loss, joint pain and strength) on six index joints (knees, elbows, ankles). The total joint score (sum of the six joint scores, range 0-120) and the global gait score (range 0 -4) provide an overall total score ranging from 0-124; 0 representing no joint impairment.

Pain was assessed with one item ranging from 0-2 per joint 10 = no pain through active range; 1 = no pain through active range; only pain on gentle overpressure or palpation; 2 = pain through active range). The latest measured joint score of the patient (total score for elbow, knee and ankle) and pain was extracted from the UMAS Haemophilia Database.

\section{Statistical analysis}

Analyses were performed using the SPSS programme version 17.0 (SPSS Inc., Chicago, IL, USA). Means (M), standard deviations (SD), medians and ranges are shown in the tables.

For the comparison between patients and partners univariate ANOVA, Student's T-Test or Chi-squared tests were used depending on the distribution of the data. A $P$-value of $<0.05$ was considered statistically significant. Correlations were calculated using Pearson product moment correlation ( $r$ ).

To determine whether the perceived burden of the disease had an impact on the HRQoL of partners of adult haemophilia patients, we calculated the median split of the summarised total score of the Caregivers' Burden Scale and compared those with a low burden to those with a high burden with respect to HRQoL scores.

\section{Results}

Of the 243 patients identified by the registry, 93 did not meet the study criteria (Table 1 ). In total 42 patients did not participate: 21 patients declined to participate or were nonresponsive $(n=21)$. Of the non-responsive group, five had a partner, but the marital status of the remaining 16 patients was unknown.

A total of 108 of 150 eligible couples (72\%) were included in the study. The majority of the couples were married (65.7\%), 32.4\% were cohabiting and $1.9 \%$ lived apart from their partner. On average, couples had been together $19.8 \pm 15.9$ years (range $1-57$ ) and had $1.7 \pm 1.3$ children (range 0-6). 


\section{Socio-demographic and clinical data}

The mean age at study entry of partners was $44.7 \pm 15.9$ years (range 20-79) and of patients, $47.1 \pm 16.0$ years (range 20-8). A significant difference was found for education level between partners and patients $(P=0.018) ; 18.5 \%$ of patients reported compulsory school as the highest level achieved compared to $8.3 \%$ of partners; $46.3 \%$ of partners had achieved an university degree, compared to only $30.6 \%$ of haemophilia patients. A significant difference was also found for working situation $(\mathrm{P}<0.0001) ; 36.1 \%$ of partners were working full-time compared to $57.4 \%$ of patients; due to haemophilia $5.6 \%$ of patients were retired and $1.9 \%$ unemployed. Compared to the general population no differences were seen in either of the groups, except for employment - a somewhat higher number of patients were unemployed [20]. Marital status for included couples was as follows: $65.7 \%$ were married, $32.4 \%$ co-habitant and $1.9 \%$ lived apart; mean number of years together was $19.8 \pm 15.9$ (1-57).

There was a significant difference in age across severity groups of haemophilia, both for patients $(P<0.001)$ and partners $(P<0.001)$. On average, couples with mild haemophilia were older compared to couples moderately or severely affected. Partners of patients with mild haemophilia had a mean age of $51.6 \pm 15.5$ years (range 20 -79), partners of moderately affected patients $45.2 \pm 15.3$ years (range 22-73) and partners of severely affected patients $38.7 \pm 14.2$ years (range $20-73$ ).

Clinical descriptors of patients in terms of type, severity and treatment of haemophilia, presence of inhibitor, viral infection, joint score and joint pain score are shown in Table 2. Significant differences among severities were found for type of treatment $(P<0.0001), H J H S$ joint score
$(P<0.0001)$ and HJHS global gait score $(P<0.002)$.

\section{Health-related quality of life}

- SF-36: Patients and their partners reported, in general, quite similar HRQoL; by contrast, partners reported significantly better HRQoL in the domains of 'physical functioning' and 'general health' (Figure 1).

Partners of patients across severities reported significantly lower HRQoL only in the domain 'emotional role' $(P=<0.041)$, with the highest impairment observed for partners of patients with moderate haemophilia.

A comparison of the scores of the study group with the general Swedish population aged 45-54 years revealed no significant differences.

Patients with moderate haemophilia reported significantly poorer HRQoL in all domains of the SF-36 except 'physical role' and 'emotional role' compared to patients with mild or severe disease. Compared to the general Swedish male population for the age group 45-54 years, their HRQoL was significantly worse for all domains except for 'social functioning', 'emotional role' and 'mental health'.

In general, the HRQoL of partners was not correlated with the HRQoL of patients. A significant correlation was found between partners and patients only for the mental component score (MCS) $(r=0.367, \mathrm{P}<0.0001)$.

- Interference with daily life (VAS): The interference of haemophilia with daily life, measured by the VAS, showed a significant difference between partners and patients $(\mathrm{P}<0.001)$; partners reported less interference with their daily life $(M=12.32 \pm 18.0)$ compared to patients $(M=23.01 \pm 28.2)$. In general, patients with milder forms of

Figure 1: Health-related quality of life of partners compared to haemophilia patients (SF-36)

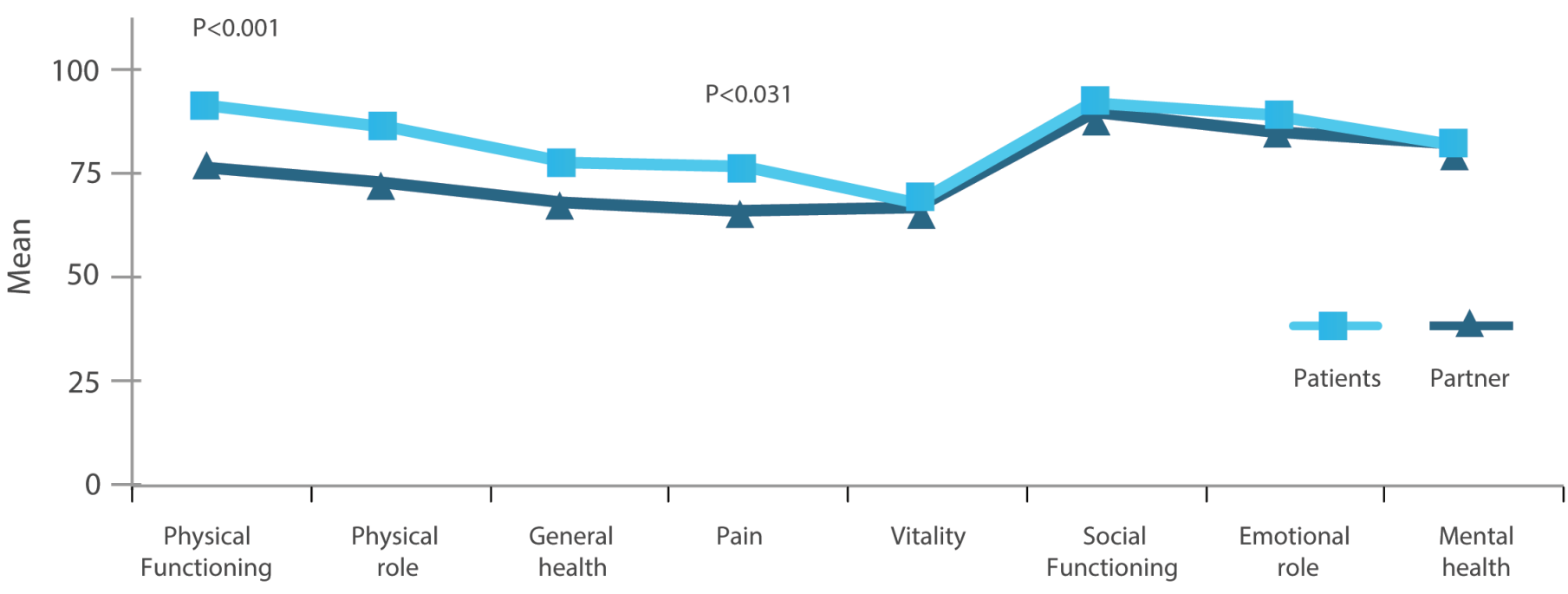




\begin{tabular}{|c|c|c|c|c|}
\hline & 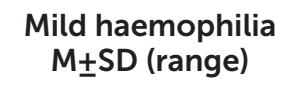 & $\begin{array}{l}\text { Moderate haemophilia } \\
\qquad M \pm S D \text { (range) }\end{array}$ & $\begin{array}{l}\text { Severe haemophilia } \\
\text { M } \pm S D \text { (range) }\end{array}$ & P-value \\
\hline Partner & $8.95 \pm 13.1(0-51)$ & $17.86 \pm 27.2(0-83)$ & $12.72 \pm 16.1(0-92)$ & n.s \\
\hline \multirow[t]{2}{*}{ Patient } & $11.10 \pm 18.5(0-93)$ & $37.10 \pm 34.1(2-93)$ & $27.15 \pm 28.7(0-100)$ & 0.001 \\
\hline & $\begin{array}{l}\text { Mild haemophilia } \\
\qquad(n=40)\end{array}$ & $\begin{array}{l}\text { Moderate haemophilia } \\
\qquad(n=21)\end{array}$ & $\begin{array}{l}\text { Severe haemophilia } \\
\qquad(n=47)\end{array}$ & $\begin{array}{c}\text { Total } \\
(n=108)\end{array}$ \\
\hline Mean age \pm SD (range) & $51.60 \pm 15.5(20-79)$ & $45.24 \pm 15.3(22-73)$ & $38.68 \pm 14.2(20-73)$ & $44.74 \pm 15.9(20-79)$ \\
\hline $\begin{array}{l}\text { General strain } \\
\text { Isolation } \\
\text { Disappointment } \\
\text { Emotional involvement } \\
\text { Environment } \\
\text { Total }\end{array}$ & $\begin{array}{l}1.28 \pm 0.4 \\
1.13 \pm 0.4 \\
1.20 \pm 0.3 \\
1.31 \pm 0.4 \\
1.23 \pm 0.3 \\
1.24 \pm 0.3\end{array}$ & $\begin{array}{l}1.39 \pm 0.6 \\
1.40 \pm 0.7 \\
1.33 \pm 0.5 \\
1.40 \pm 0.5 \\
1.37 \pm 0.5 \\
1.37 \pm 0.5\end{array}$ & $\begin{array}{l}1.36 \pm 0.4 \\
1.21 \pm 0.4 \\
1.21 \pm 0.4 \\
1.31 \pm 0.5 \\
1.34 \pm 0.5 \\
1.29 \pm 0.4\end{array}$ & $\begin{array}{l}1.33 \pm 0.5 \\
1.21 \pm 0.5 \\
1.23 \pm 0.4 \\
1.33 \pm 0.4 \\
1.31 \pm 0.4 \\
1.29 \pm 0.4\end{array}$ \\
\hline
\end{tabular}

Mean score 1 to 1.99 indicates low burden, 2 to 2.99 medium burden and 3 to 4 high burden

No significant difference across severity groups

haemophilia felt significantly less interference with their daily life $(P<0.001)$, and patients with moderate disease reported greater interference than severe patients. By contrast, no significant differences were found for their partners (Table 3).

Partners who reported a high degree of interference in daily life based on the median split (>6) had lower HRQoL in the domains of 'vitality' $(P<0.013)$, 'emotional role' $(P<0.022)$ and 'mental health' $(P<0.003)$ of the SF-36 compared to those who reported low interference $(<6)$.
- Caregivers' Burden: Partners reported, in general, a low burden of haemophilia in the Caregivers' Burden Scale $(M=1.29 \pm 0.4)$. No significant differences across severity groups of haemophilia patients were found (Table 4). 'Emotional involvement' was the biggest burden in the mild $(M=1.31 \pm 0.4)$ and moderate groups $(M=1.40 \pm 0.5)$, while in the severe group 'general strain' was the biggest burden ( $M=1.36 \pm 0.4)$. In addition, 'isolation' was a substantial burden in partners of those with moderate haemophilia $(M=1.40 \pm 0.7)$.

Figure 2 HRQoL (SF-36) in partners with low vs. high Caregivers' Burden (summarised total score)

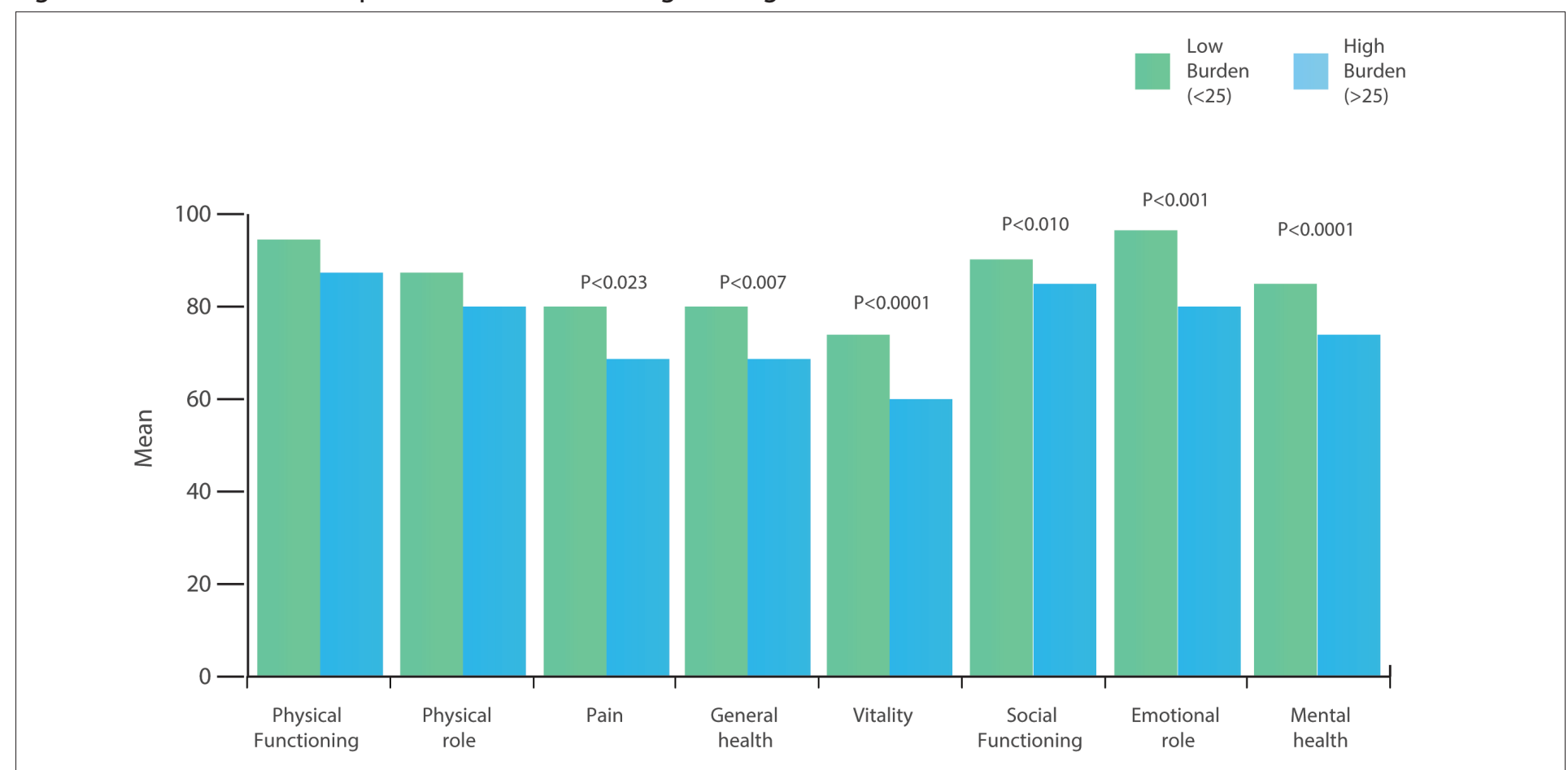


No difference was found between the caregiver's burden of partners of haemophilia patients with HIV infections $(n=7)$ and those without HIV infections.

Partners burden was highly correlated $(r=-0.498$,

$\mathrm{P}<0.0001$ ) with the mental component score of their own HRQoL, but not with their own physical component score. By contrast, the burden of partners was highly correlated with the physical component score $(r=-0.408, P<0.001)$ and the orthopaedic status (HJHS) of haemophilia patients $(r=-0.354, P<0.001)$. No correlation was found between partners' burden and patients' mental component score (SF-36).

When partners were divided into two groups defined by low $(<25)$ or high ( $>25$ ) Caregivers' Burden at the median split of the summarised total score, those partners who reported high burden had lower HRQoL in almost all domains of the SF-36, except 'physical role' and 'physical functioning' compared to those who reported a low burden (Figure 2).

\section{Discussion}

Caring for a person with a chronic disease is burdensome and stressful and can lead to decreased HRQoL and early mortality for the caregiver [21]. To arrive at a better understanding of the extent to which haemophilia might impact the partners of haemophilia patients, we evaluated their HRQoL and caregivers burden. Our rationale for doing so is that it is the responsibility of the HTC providing comprehensive care to involve the entire family of the patient, and not least the partner.

In general, partners reported good HRQoL and low impact of the disease in the Caregivers' Burden Scale. However, partners of patients with moderate haemophilia seemed to have the highest negative impact; they reported higher burden compared to other severities in the domain 'isolation', which was likely due to decreased socialising with friends and decreased opportunities to do what they may have wished to do at this time in their lives. For the domain 'disappointment' loneliness and isolation due to their partners' disease was an issue; they reported the highest total burden. Up to $10 \%$ of moderately and severely affected haemophilia patients in our cohort were HIV positive, which one could assume to cause an additional burden for their partners, although this could not be proven. In general, the impact of the disease was quite low compared to another study in which caregivers' burden was assessed among spouses of people with dementia, in which a higher burden was observed [22]. In addition to their older age we noted a lower participation rate for couples in the moderate group compared to that of the severe group. To be considered is the fact that some patients with moderate haemophilia did not begin prophylaxis until later in life and had already developed haemophilic arthropathy. Most moderate patients in this study had high HJHS irrespective of their current type of treatment. Advanced joint disease may account for the observation of higher interference and lower HRQOL, which likely also has an influence on the partner. It is plausible to hypothesise a more problematic scenario for the moderate group: lack of prophylactic treatment may increase anxiety regarding risk for bleeding resulting in less physical activity, which also could have an impact on the partners in this group. This finding points to a need for increased vigilance at the haemophilia treatment centre for patients with moderate disease and their partners.

As the partners of those with mild haemophilia were older compared to those in the moderate group and reported a lower impact of haemophilia, the differences between the moderate and the somewhat younger severe group are unlikely attributable to age differences The moderate patients who participated in this study were patients that come for their regular comprehensive visits once per year, i.e., as frequently as the patients with severe disease, which may indicate that they are comparably affected by the disease. Moderate patients with no prophylactic treatment and less contact with the haemophilia treatment centre were somewhat less likely to participate in the study, which may have introduced a bias. By contrast, virtually all patients with severe haemophilia who participated had regular prophylaxis and a tighter connection to the haemophilia treatment centre. One might expect that partners of patients with severe haemophilia who reported lower HRQoL in the SF-36 compared to the general population would report higher interference of haemophilia in daily life on the VAS scale, but this was not the case. It is likely that prophylactic treatment has a positive impact on partners as well as on patients, i.e., reduced risk for bleeds increases the possibilities for physical activity for both family members. A majority of eligible patients with severe and moderate haemophilia ( $92 \%$ and $75 \%$, respectively) took part in the study; however, only $56 \%$ of patients with mild haemophilia participated. As has been reported in previous investigations [23], patients with mild haemophilia show less involvement in research, perhaps due to few or no problems with the disease in their daily lives. This is a weakness of our and other studies but it may also be a reflection of low impact of the disease, particularly as this patient group attends less regularly for clinical check-ups than the more severe patients. While we had no control group of partners of subjects without haemophilia, we did have available for comparison the SF-36 norms for the general Swedish population [16] as well as caregivers burden data available for partners of persons with other chronic conditions [22].

\section{Conclusion}

As the population with haemophilia is aging, partners will likely become more involved in the care of patients, particularly as age-related co-morbidities complicate the bleeding disorder and the responsibility for treatment may be transferred from the patient himself to his partner. Comorbidities will add to the burden of the existing disease 
and impact the well-being of partners of patients. The haemophilia treatment centre should not only focus on the patient with haemophilia but should take a more holistic approach to care of the patient and his family. To achieve a better understanding of the needs and demands of the family, it is important that the patient brings his partner with him to clinical check-ups. Special attention should be paid to partners of patients with moderate haemophilia, as this group seems to be especially burdened by the partners' disease.

\section{Author contributions}

$\mathrm{KL}$ and EB designed the study. SVM analysed the data. SE contributed with expertise and $\mathrm{KL}, \mathrm{SVM}$ and $\mathrm{EB}$ wrote the paper. All authors contributed to the writing and revision of the paper.

\section{Disclosures}

This study was supported with funds from Baxter Nordic, Sweden, The Arosenius Fund and regional fund (ALF).

\section{References}

1. White GC n, Rosendaal F, Aledort LM, et al. Definitions in hemophilia.

Recommendation of the scientific subcommittee on factor VIII and factor IX of the scientific and standardization committee of the International Society on Thrombosis and Haemostasis. Thrombosis and Haemostasis 2001; 85(3): 560.

2. Manco-Johnson MJ, Riske B, Kasper CK. Advances in care of children with hemophilia. Semin Thromb Hemost 2003; 29: 585-94.

3. Manco-Johnson MJ. Update on treatment regimens: prophylaxis versus ondemand therapy. Semin Hematol 2003; 40: 3-9.

4. Manco-Johnson M. Comparing prophylaxis with episodic treatment in haemophilia A: implications for clinical practice. Haemophilia 2007; 13 Suppl 2: 4-9. 10.1016/j.blre.2009.08.001

6. Gringeri A Lundin B, von Mackensen S, et al. A randomized clinical trial of prophylaxis in children with hemophilia A (the ESPRIT Study). J Thromb Haemost 2011; 9(4): 700-10. doi: 10.1111/j.1538-7836.2011.04214.x.

7. Nilsson IM, Berntorp E, Lofqvist T, Pettersson H. Twenty-five years' experience of prophylactic treatment in severe haemophilia A and B. J Intern Med 1992; 232(1): 25-32.

8. Lindvall K, Von Mackensen S, Berntorp E. Quality of life in adult patients with haemophilia--a single centre experience from Sweden. Haemophilia 2012: 18(4): 527-31. doi: 10.1111/j.1365-2516.2012.02765.x

9. Larsson SA. Life expectancy of Swedish haemophiliacs, 1831-1980. Br J Haematol 1985; 59(4): 593-602

10. Mauser-Bunschoten EP, Fransen Van De Putte DE, Schutgens RE. Co-morbidity in the ageing haemophilia patient: the down side of increased life expectancy. Haemophilia 2009; 15(4): 853-63. doi: 10.1111/j.1365-2516.2009.01987.x.

11. Street A, Hill K, Sussex B, et al. Haemophilia and ageing. Haemophilia 2006; 12 Suppl 3: 8-12.

12. Siboni SM, Mannucci PM, Gringeri A, et al. Health status and quality of life of elderly persons with severe hemophilia born before the advent of modern replacement therapy. J Thromb Haemost 2009; 7(5): 780-6. doi: 10.1111/j.1538 -

7836.2009.03318.x.

13. Franchini M, Mannucci PM. Co-morbidities and quality of life in elderly persons with haemophilia. Br J Haematol 2010; 148(4): 522-33. doi: 10.1111/j.1365-

14. Lindvall K, Swedenborg N. UMAS Hemophilia Database. Stud Health Technol Inform. 2006; 122: 853 .

15. Ware JE, Jr. Sherbourne CD. The MOS 36-item short-form health survey (SF36). I. Conceptual framework and item selection. Med Care 1992; 30(6): 473-83. 16. Sullivan M, Karlsson J, Ware JE J. The Swedish SF-36 Health Survey--

Evaluation of data quality, scaling assumptions, reliability and construct validity across general populations in Sweden. Social Science \& Medicine 1995; 41(10) 1349-58

17. Huskisson EC. Measurement of pain. Lancet. 1974; 2(7889): 1127-31.

18. Elmstålh S, Malmberg B, Annerstedt L. Caregiver's burden of patients 3 years after stroke assessed by a novel caregiver burden scale. Arch PhysMed Rehabil 1996: 77(2): 177-82.

19. Hilliard P, Funk S, Zourikian $N$, et al. Hemophilia joint health score reliability study. Haemophilia 2006; 12(5): 518-25

20. Data on Swedish unemployment rate. [cited 201313 February 2013]; Available from: www.scb.se

21. Schulz R, Beach SR. Caregiving as a risk factor for mortality; the Caregiver Health Effects Study. J Am Med Assoc 1999: 282: 2215-9. 22. Andrén S, Elmstålh S. Family caregivers subjective experiences of satisfaction in dementia care: aspects of burd

23. Lindvall K, Colstrup L, Loogna K, et al. Knowledge of disease and adherence in adult patients with haemophilia. Haemophilia 2010; 16(4): 592-6. doi:

10.1111/j.1365-2516.2009.02189.x.

\section{The Journal of \\ Haemophilia Practice}

An open-access journal for sharing experience in the care of people with bleeding disorders

\section{www.haemjournal.com}

